\title{
Research on Passenger Seat Choice Behavior in Airline Revenue \\ Management
}

\author{
Xixi Zeng and Yue Li \\ College of Music ,Jiangxi University of Technology
}

Keywords: Air transport; Revenue management; Seat control; Consumer behavior; Passenger choice

\begin{abstract}
Along with the gradually growing fierce competitions in air transport market, all large airline companies are seeking ways to increase revenues and enhance competitiveness, setting basis for application of revenue management system in domestic market. Taking revenue management theory as the background and combined with existing research results of passenger choice behavior theory, in the thesis, exploratory researches on airline passenger seat choice are made. Analysis on passenger seat choice behavior from the aspect of consumer behavior theory, and choice preference and choice probability of passengers under the circumstance of different seat classes in the same flight are researched. This thesis includes the following aspects: firstly, reviewing history of revenue management development, pointing out the main direction of the research, summarizing theory, research history and current status of discrete choice model and PODS passenger choice model in details and analyzing similarities and differences between applications the two models. Secondly, applying discrete choice model and analytic hierarchy process to establish passenger seat choice model and estimating parameters of the established model, then further analyzing application of this model in seat inventory control. Thirdly, discussing application status of the passenger choice model through investigation, and comparing with the actual survey results to prove practicability and validity of the established model.
\end{abstract}

\section{Introduction}

Chinese civil aviation realized actual takeoff after economic reform. During the period from 1980 to 1990, annual average growth rate of air transport market reached to 19\%, and in the first years of 1990s, annual average growth even reached up to $27 \%$, meaning Chinese civil aviation transport went through a "honeymoon" period. However, along with changes of internal and external environment of aviation market, former management system could not adapt to market changes, therefore Civil Aviation Administration of China took measure of "price deregulation" in 1997 which led to price wars among all airline companies and the whole industry suffered huge losses of 2.44 billion Yuan in 1998 as a consequence.

In order to eliminate the losses, Civil Aviation Administration of China had to issue the order of prohibiting discounts in the whole industry in 1999. But airline companies are enterprises after all whose market behaviors have independent operational rules which are beyond the will of human beings. So all airline companies offered discounts secretly, which led to competitive chaos in the domestic civil aviation transport market. With our country joining WTO and speed up of economic globalization, competitions in air transport are growing more fierce, thus all airline companies are 
trying to gain more market shares through seek product differences and to obtain more incomes. Foreign airline companies mostly adopt revenue management, am advanced management technology, to enhance competitiveness and increase revenues.

In foreign companies, researches on revenue management are already with more than 40-year history, focusing on five aspects of predicting, overbooking, seat inventory control, passenger behavior and pricing. Lots of famous economists, operation research experts, managerialists and transport experts have joined in this research field, which makes abundant achievements in this field. Wherein, passenger choice behavior research is a main development direction of revenue management research, however, in China, there are no researches related to passenger choice behavior. Therefore, analyzing passenger characteristics and researching passenger seat choice behavior are extremely necessary for domestic airline companies.

In this thesis, based on theories of econometrics, consumer behavior, operational research, probability theory and statistics, exploratory research on passenger seat choice behavior in the field of airline revenue management is carried out in the thinking mode of raising questions, qualitative analysis, establishing model and contrastive analysis.

Econometric theory is applied in analysis of passenger choice model; and in analysis of air passenger seat choice behavior, consumer behavior theory is applied combined with utility theory, then utility of passenger- seat class is gained as a result. When building passenger seat choice model, passenger utility is considered as the primary purpose, operational research theory and principle of probability and statistics are applied in building passenger seat choice model, and further analyzing and verifying accuracy and applicability of the model based on survey data.

\section{Development History and Research Direction of Revenue Management}

Revenue management (RM) is a market-oriented process of determining best price and best inventory allocation strategy to realizing maximum revenue through subdividing market and analyzing and predicting consumer behaviors in each sub-markets. Emergency and development of revenue management are closely related to developments of theories of operational research and management science, computer technology, industrial policy and market. Generally speaking, revenue management shall have three basic conditions: application condition- development of air transport; theory condition- development of operation research and management science; and technology condition- development of computer and network technology. Developments of these three conditions are parallel, and their combination is pushing development of revenue management.

Revenue management is the spontaneous extension of management activities, price strategies and seat control of airline companies, but the fundamental theory is not changed. Along with changes of internal and external environment of air transport, gradually increase of competitors in airline market and diversities of passenger demands, complexity of revenue management problems becomes increasingly higher. Development process of revenue management approximately goes through the following three stages:

Stage of taking advantage of "residual seats" to increase flight revenue. Due to inherent change rules of passenger demands, there is no possibility for an airline company to sell all seats to passengers with full-fair, so residual seats are inevitable. Therefore, necessary management shall be carried out. Business operations of airline companies involve the following two aspects: one is increasing flight revenue making use of overbooking technology: in order to reduce residual seats and improve passenger seats use rate, overbooking is an effective way to increase flight revenue. 
Operational approach is to estimate amount of residual seats according to booking and boarding and seat cancellation, and then implement different overbooking methods. This method is effective in busy flights, while not good in flights with fewer demands. The other one is increasing flight revenue with discounted tickets: according to the premise that passengers with normal ticket price can share fixed costs of the flight, so long as price of the discount ticket is higher than costs generated from adding one more passenger, the airline company can gain revenue, which theory provides basis for airline companies to increase revenue with discounted tickets. But this method is only applicable to flights with high density.

Stage of taking advantage of multi-level ticket price structure to increase flight revenue. Along with changes of passenger behavior and demands features, air transport market is divided more detailed increasingly, which is because during the process of residual seats management, the more price levels are, the higher degree for airline companies meeting each kind of sub-market demands is, and the higher revenue airline companies will get as well. When airline companies adopt multi-level ticket price structure, risks also exist. Because this will cause passengers buying high-price tickets choose to buy tickets of lower level seats, therefore requiring airline companies to put forward relevant restriction conditions on purchase and use of cheaper tickets and to provide various rewards and first-rate services for passengers in first-class cabins and business class cabins or passengers buying full-fare tickets as well.

Stage of taking advantage of flow control to optimize airline network. Previously, when conducting flight economic analysis, airline companies carried out statistics and analysis on basis of leg, striving to realize maximum revenue in this leg. However, maximum leg revenue neither equal maximum segment revenue, nor equal maximum airline network revenue. Changing airline network structure to spoke airline network structure can reduce operational costs of airline companies largely, but large amount of connection flights made airline structure complex, and plus with release of multi-level ticket price, revenue management of airline companies became more complicated.

\section{Discrete Choice Model}

Discrete choice model is a very effective and practical market research technology. This model is mainly used to see how consumers will choose different products or services under actual or simulated market competition environment. Generally, purchasing behaviors of consumers are measured through stimulating market competition environment of the products or services on basis of experimental design, thus knowing how consumers would choose under different attribute level and prices of products or services. At present, this technology is widely applied into exploring choice behaviors of decision makers under the circumstance that options are limited and discrete.

Binary choice problems always occur in actual life. For instance, to take public transport means or private vehicles to go to work is a problem; whether to buy a commodity or not is a problem; and to accept or refuse a job offer is a problem for a job seeker. All these are binary choice problems. Fields involved in these problems may be different though, large statistical researches show that a casual link is between factors affecting decision makers and the choices. And revealing the casual relationship and applying it into prediction study have important significances on economic development of the society.

When researching passenger seat choices, provided that there are two levels of high and low ticket price and passengers can only choose from these two seats. A passenger choosing a seat with high price will be given in the formula of $\mathrm{y}=1$ and a passenger choosing a seat with low price will be 
given in the formula of $\mathrm{y}=0$. Data of $\mathrm{N}$ passengers can be look into and based on which study relations between choices of $\mathrm{N}$ passengers and factors affecting choices can be made. Given binary variable is y and $\mathrm{i}=1,2 \cdots, \mathrm{N}$, which represent seat choices of passenger. Hence:

When the i passenger chooses seat with high price, then $y_{i}=1$;

When the i passenger choose seat with low price, then $y_{i}=0$.

Given that $\mathrm{X}$ means factors affection passenger seat choices, generally, $\mathrm{X}$ is an order vector including $\mathrm{r} \times 1$, and $\mathrm{x} \in \mathrm{X}$, then:

$$
P\left(y_{i}=1 \mid X\right)=F(x, \beta)
$$

$\beta$ is a $r \times 1$ unknown parameter vector, $F(x, \beta)$ determines probability of $y=1$ under the condition of given x. Observed decision behavior is defined as a random variable $y_{i}$

$$
y_{i}= \begin{cases}1 & \text { if } \mathrm{y}_{\mathrm{i}}>0 \\ 0 & \text { if } \mathrm{y}_{\mathrm{i}}<0\end{cases}
$$

\section{PODS Passenger Choice Model}

PODS (Passenger Origin-Destination Simulator) is a simulator of passenger origin-destination which is a computer simulation tool to survey revenue management technology of airline companies. It was firstly put forward by Hopperstad, Berge and Filipowski of Boeing Company as an extension of decision-making window model to research influences of flight time on market shares of airline companies. As a revenue management experience instrument, PODS is at the service of PODS Association which constitutes MIT (Massachusettes Institute of Technology) and seven major international airline companies.

PODS is consisted of four parts: history booking database, prediction module, seat inventory control of revenue management and passenger choice model. Structural relations of these four parts are as follows:

History data are generated from past booking records and history data of booking are used to predict future flights. Prediction demand is the second component of PODS. Prediction personnel shall set booking limits for flights to depart, and people responsible for revenue management optimization shall input prediction demands according to data features of revenue management method. Prediction process will be assumed as seat class demands prediction in the next paragraph and this process is similar to route demands prediction.

PODS passenger choice model is designed based on some researches done by Boeing Company, especially decision-making window model of Boeing. It mainly has the following four steps: firstly, generating air travel demands; secondly, defining characteristic set of each passenger and simulating his/her choice preference; thirdly, determining choice sets of passengers according to characteristics of passengers and seat inventory of airline companies; and lastly, passengers making decisions according to self characteristics and option properties. Refer to Fig. 1. 


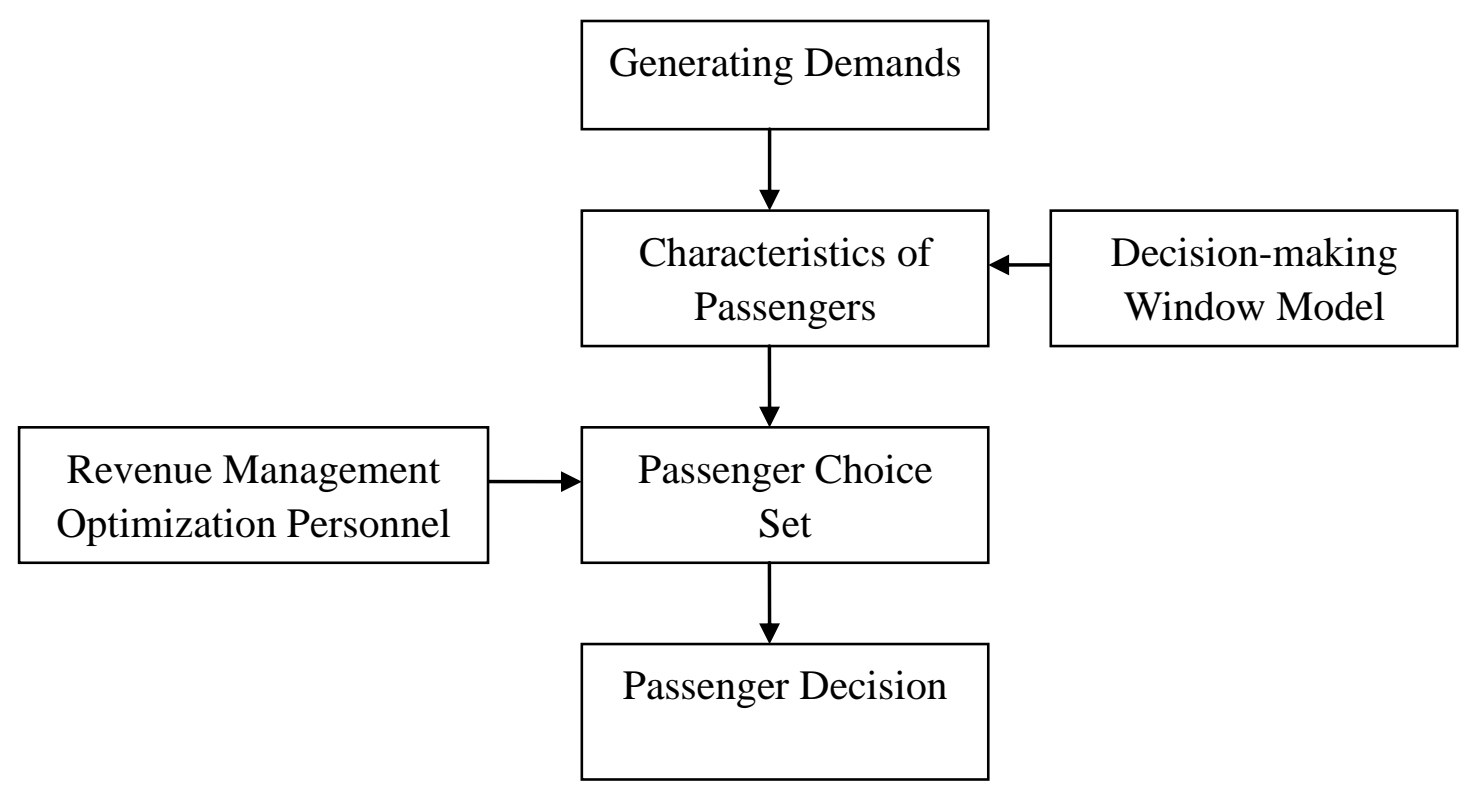

Fig. 1 Structure of PODS Passenger Choice Model

At present, decision rules of PODS have made distinctions between monetary factor (maximum willingness to pay) and non-monetary factor (disutility). Choice on specific route or seat class is based on these two factors, while this choice is limited by maximum willingness to pay, and only route or seat class lower than maximum willingness to pay is effective in passenger choice set.

\section{Applying Consumer Behavior Theory to Analyze Seat Inventory Control}

Consumer behavior refers to behaviors of consumers influenced by demand motive to decide to purchase, modify purchase plan and accomplish purchase process. Consumer behavior is a process. Refer to Fig. 2 for its general model. In the early stage of consumer behavior, it usually meant behaviors of buyer and emphasized on interaction effects between consumers and manufacturers when consumers were buying. Now many manufacturers realize that consumer behavior is a continuous process which involves all matters influencing consumers before, at and after purchase, while not only the process of consumers getting commodities or services after paying cash or paying by credit card.

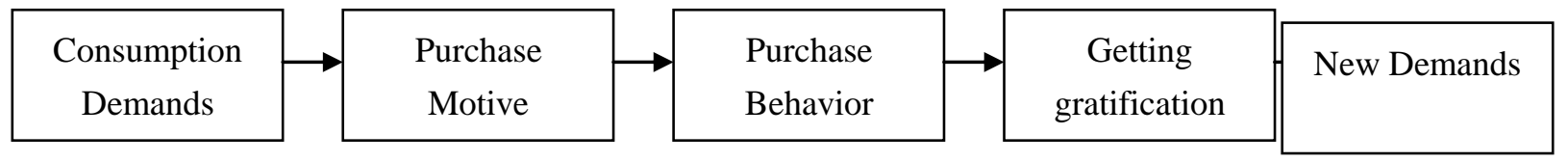

Fig. 2 General model of consumer purchase behavior

Consumer behavior process is not only a thinking and mental process, but also a process of consumers continuously taking actions, making plans and solving problems. Factors affecting consumer behavior have social, historical and economic factors which are extremely complicated. J.M. Keynes once pointed out that consumption motive or saving motive was a habit generated from assumed economic system, economic organizations, races, education, conventions, religions and prevalent moral ideas, and it differed a lot along with the resent hope and past experience, number of investments and technological equipment, present wealth distribution method and established life 
style of all levels of society. It is the responses of people to products and services and marketing activities related to such products and services that consumer behavior theory researches.

\section{Utility Theory and Consumer Preference}

As a rational consumer, when choosing from different seat classes, each air passenger would like to measure economically whether consumption demand gratification degree is in proportion to consumption expenses with his/her own preference, trying to satisfy his/her personal preference and maximize aggregate utility as well, and then decide seat class to purchase hereunder.

Objectively, utility value depends on performance or service level of commodities, and subjectively, it relies on judgments of consumers to serviceability or service level of commodities. It is usually assumed in microeconomics that consumers always tend to pursue maximum utility when making choices. The following two aspects shall be noticed when understanding utility:

Firstly, utility is a subjective feeling which totally depends on individual satisfaction degree of consuming some kind of goods. Utility has neither any ethics meanings nor objective criterion. Utilities of a same commodity to different people at different time and places are different.

Secondly, utility is a subjective mental feeling, though when researching consumer behavior with cardinal utility theory, assumed utility can be measured, therefore, utility unit is taken to indicate utility. This measurement unit is selected randomly. In fact, taking some kind of unit to measure something is only for convenience of researches while not actual measure. When researching consumer behavior, utility unit is used as a kind of analysis tool. In some sense, measurement units are all determined artificially and subjectively, and no matter units are specific or abstract, so long as they are in favor of the analysis, all of them can be used. Utility unit is exactly determined for researches of consumer behavior.

\section{Conclusions}

In this thesis, taking passenger choice behavior in revenue management as principal research object, development history and results of researches on revenue management and passenger choice behavior are concluded and summarized, airline passenger seat choice behavior is analyzed from the aspect of consumer behavior theory, passenger choice preference and passenger choice probability of different seat class are researched under the situation of same flight and different seat class, and calibration model is established, and lastly, analysis in combination of market survey examples is made. Specifically, major work and innovation points of this thesis are shown in the following aspects:

Summary of research history of revenue management and passenger choice model. Through reviewing development history of revenue management, future research development direction is pointed out. Summary of theory, research history and present status of discrete model and PODS passenger choice model is made in details, and similarities and differences between these two methods during application is compared.

Applying consumer behavior theory to analyze passenger seat choices. Researches on passenger seat class choices from the aspect of consumer behavior theory are made. Through analysis of passenger utility and preference, subjective and objective and random factors influencing passenger seat choices are determined. Necessity to analyze passenger sear choice problem from consumer 
aspect is put forward, and significances of researches on passenger seat choice are set forth from two aspects of revenue management development and marketing.

\section{References}

[1] Wang Zhi, Views on Civil Aviation Based on Statistics (2002), Beijing, China Civial Aviation Press, 2002: 37-48

[2] Yang Siliang, Liu Jun, some basic concepts of air transport revenue management, Civil Aviation Economy and Technology, 1998, No. 196, 37-41

[3] Liu Jun, Researches on Air Transport Revenue Management and Risk Decision Theory and Applications, [doctoral dissertation], Beijing, Beijing University of Aeronautics and Astronautics, 2000

[4] E.L.Williamson, Airline Network Seat Inventory Control: Methodologies and Revenue Impacts, PhD thesis, Flight Transportation Laboratory ,Massachusetts Institute of Technology, Cambridge, MA, 1992

[5] Liu Jun, Background and Conditions of Revenue Management Development, China Civil Aviation, 2001(2):43-46

[6] Pang Qing, Primary Explores on Revenue Management of Domestic Air Transport, [master thesis], Shanghai, Fudan University, 2000

[7] Xu Gongda, Shi Liya, Air Transport Management, Beijing: Aviation Industry Press, 2003: $102-121$

[8] Weatherford L.R, Bodily S.E. A Taxonomy and Research Overview of Perishable-asset Revenue Management: Yield management, Overbooking and Pricing

[J]. Operations Research, 1994, 40: 831 844

[9] McGill J I, Van Ryzin G J. Revenue Management: Research Overview and Prospects

[J]. Transportation Science, 1999, 33: 233 256

[10] Zhou Yan, Researches on Recall System of Seat Inventory Control in Revenue Management, [master thesis], Nanjing, Nanjing University of Aeronautics and Astronautics, 2005 